\title{
Molecular structure, vibrational spectra and photochemistry of 5-mercapto-1-methyltetrazole
}

\author{
A. Gómez-Zavaglia ${ }^{\text {a,b }}$, I.D. Reva ${ }^{\text {a }}$, L. Frija ${ }^{c}$, M.L. Cristiano ${ }^{c}$, R. Fausto ${ }^{\text {a,* }}$ \\ ${ }^{a}$ Department of Chemistry, University of Coimbra, R. Larga, 300 4535, Coimbra, Portugal \\ ${ }^{\mathrm{b}}$ Facultad de Farmacia y Bioquímica, Universidad de Buenos Aires, Buenos Aires, Argentina \\ ${ }^{\mathrm{c}}$ Department of Chemistry and Biochemistry, University of Algarve, Faro, Portugal
}

Received 3 August 2005; revised 12 August 2005; accepted 13 August 2005

Available online 28 September 2005

\begin{abstract}
In this work, 5-mercapto-1-methyltetrazole was studied by low temperature matrix-isolation and solid-state infrared spectroscopy, DFT(B3LYP)/6-311 + + G(d,p) calculations and photochemical methods. In the low temperature neat solid phase and isolated in an argon matrix, the compound was found to exist in the 1-methyl-1,4-dihydro-5H-tetrazole-5-thione tautomeric form. The infrared spectra of the compound were fully assigned and correlated with structural properties. In situ UV-irradiation $(\lambda>235 \mathrm{~nm})$ of the matrix-isolated monomer is shown to induce different photochemical processes, all of them involving cleavage of the tetrazole ring: e.g. (1) molecular nitrogen expulsion, with production of 1-methyl-1H-diazirene-3-thiol, which is produced in two different conformers; (2) ring cleavage leading to production of methyl isothiocyanate and azide; (3) simultaneous elimination of nitrogen and sulphur with production of $N$-methylcarbodiimide. Following these photoprocesses, subsequent reactions occur, leading to production of methyl diazene, carbon monosulphide and nitrogen hydride. Spectroscopic evidence of the production of the above-mentioned chemical species is provided.
\end{abstract}

(C) 2005 Elsevier B.V. All rights reserved.

Keywords: 5-Mercapto-1-methyltetrazole; Matrix-isolation infrared spectroscopy; Photochemistry; $N$-methylcarbodiimide; 1-Methyl-1 $H$-diazirene-3-thiol; Methyl isothiocyanate; Azide; Methyl diazene; Carbon monosulphide; Nitrogen hydride

\section{Introduction}

Tetrazoles have received much attention due to their important industrial and biological practical applications [1,2]. In particular, 5-mercapto-1-methyltetrazole (1-methyl$1 H$-tetrazole-5-thiol; MTT) has been used in the synthesis of pharmacologically active cephalosporins [3] and, as cesium salts, as part of the thiolate/disulfide redox couple [4]. It has also been demonstrated that MTT increases prothrombin time and decreases plasma factor VII and prothrombin levels in vitamin K-deficient male rats [5].

From a more fundamental point of view, MTT is also a very interesting compound because of two main factors: firstly, the existence of different possible tautomers (Fig. 1), including thiol and thione tautomeric forms; secondly, its expectable rich photochemical reactivity, as it was previously observed for other tetrazole derivatives [6-12].

\footnotetext{
* Corresponding author. Tel.: +35 1239 852080; fax: +35 1239827703.

E-mail address: rfausto@ci.uc.pt (R. Fausto).
}

0022-2860/\$ - see front matter (C) 2005 Elsevier B.V. All rights reserved. doi:10.1016/j.molstruc.2005.08.019
The fact that tautomerism influences the reactivity of the mercapto-azoles (including tetrazoles) has been demonstrated for both polymerization processes and substitution reactions in different moieties [13-15]. For example, 2,5dimercapto-1,3,4-thiadiazole exists in the thione-thiol form in the solid state [16], whereas in solution a solventdependent equilibrium is believed to exist between the thione-thiol and thione-thione tautomers, the former being the prevailing species in polar solvents [14]. On the other hand, for 2-mercapto-5-methyl-1,3,4-thiadiazole, the thione form exists predominantly in DMSO solution as well as in the solid state [14,17]. The thiol-thione tautomerism in mercapto-azoles has, in fact, been a point of controversy for many authors, thus justifying further investigation on this topic using complementary experimental and theoretical methods that may provide a deeper insight on this problem. In this regard, matrix isolation spectroscopy appears as a very powerful technique. In a low temperature inert matrix (typically $10 \mathrm{~K}$ ), the studied guest molecules do not rotate and also the effects of inhomogeneous broadening of the vibrational bands are minimized. As a result, the vibrational bands in the spectra of matrix isolated compounds become 


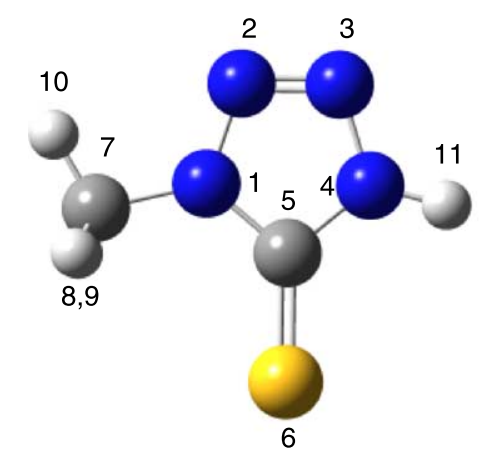

1-methyl-1,4-dihydro-5H-tetrazol-5-thione $\mathrm{E}=-1826828.5 \mathrm{~kJ} \mathrm{~mol}^{-1} ; \mu=1.50 \mathrm{D}$

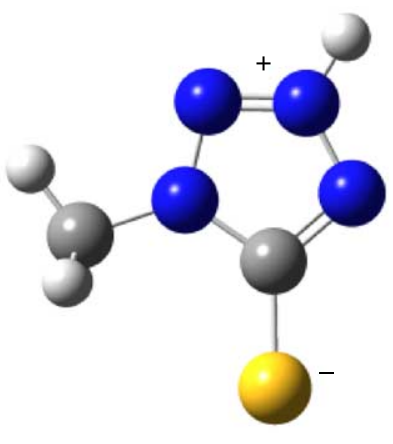

1-methyl-1H-tetrazol-3-ium-5-thiolate $\Delta \mathrm{E}=65.0 \mathrm{~kJ} \mathrm{~mol}^{-1} ; \mu=6.27 \mathrm{D}$

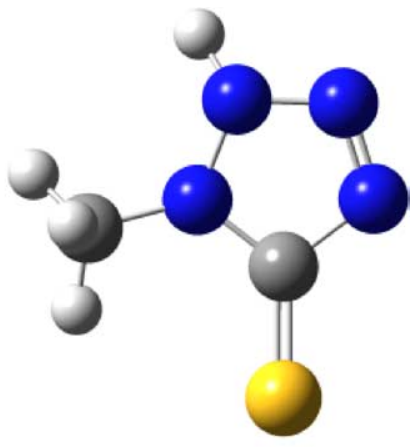

1-methyl 1,2-dihydro-5 $\mathrm{H}$-tetrazol-5-thione $\Delta \mathrm{E}=104.5 \mathrm{~kJ} \mathrm{~mol}^{-1} ; \mu=7.00 \mathrm{D}$

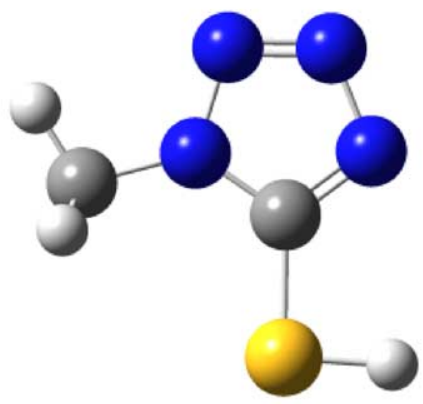

1-methyl-1 $H$-tetrazol-5-thiol

A $\Delta \mathrm{E}=32.5 \mathrm{~kJ} \mathrm{~mol}^{-1} ; \mu=5.24 \mathrm{D}$

$\Delta \mathrm{E}=41.7 \mathrm{~kJ} \mathrm{~mol}^{-1} ; \mu=6.29 \mathrm{D}$

B

Fig. 1. Tautomers of MTT, with atom numbering. Calculated relative energies (with zero point correction) and dipole moments are also shown.

very sharp and narrow. Thus the main advantage of the matrix-isolation approach is then the possibility of attaining relatively high spectroscopic resolution, facilitating the structural characterization of the monomeric species of the compound and the identification of spectral signatures of different tautomers or conformers, which are usually closely located in the spectrum (within a few wavenumbers). Another advantage is that the low temperature conditions can be used to trap and spectroscopically identify at least some of the chemical species produced in low amounts during photolysis, which in other conditions (e.g. at room temperature) are very reactive, or those with intrinsically low-intensity IR absorptions. Finally, owing to the high resolution of the method and inert environment, it becomes possible to compare directly the experimental spectra with the results of theoretical calculations.

The photochemistry of tetrazoles in general has been the subject of several studies by different methods, including matrix-isolation infrared spectroscopy [6-12]. All these studies demonstrated that, in general, cleavage of the tetrazole ring occurs after UV-irradiation. However, the precise nature of the substituents present in the tetrazole ring was found to strongly determine the final photoproducts. In spite of the fact that it can be expected to be as rich as for other tetrazoles already studied, the photochemistry of mercaptotetrazoles has not yet been subjected to detailed investigation. To the best of our knowledge, only the 20 years old study of Quast and Nahr [18] has been reported hitherto. In that study, the photochemistry of some 1-phenyl5 -mercaptotetrazoles was investigated in solution and carbodiimides, phenylcyanamide, molecular nitrogen and sulphur were found to be main products [18] resulting from photolysis. On the other hand, thermochemical reactivity of this kind of compound has been analyzed by different techniques [19-22]. In the gaseous phase, thermolysis of MTT was studied by real-time gas analysis controlled by photoelectron spectroscopy and it was found to follow three main different pathways, yielding (a) methyl isothiocyanate + azide, (b) methyl azide + isothiocyanic acid and (c) molecular sulphur/sulphidric acid + molecular nitrogen $+N$-methylcarbodiimide [19]. A multitude of possible photochemical reaction pathways, leading to different products, can also be foreseen. The fact that in a matrix the processes are cage-confined (molecular diffusion is inhibited) introduces a useful simplification to the study of the photochemical reactivity, since no cross-reactions can, in principle, take place and only primary unimolecular reactions are expected. These characteristics give further support to the approach followed in the present study.

Hence, in this work, the structure, vibrational spectra and UV-induced photochemistry of MTT were studied by matrixisolation and low temperature solid-state infrared spectroscopy, supported by extensive DFT(B3LYP)/6-311++ $\mathrm{G}(\mathrm{d}, \mathrm{p})$ calculations. 


\section{Materials and methods}

\subsection{Infrared spectroscopy}

MTT was obtained from Aldrich (purity $>99 \%$ ). The IR spectra were obtained using a Mattson (Infinity 60AR Series) Fourier Transform infrared spectrometer, equipped with a deuterated triglycine sulphate (DTGS) detector and a $\mathrm{Ge} / \mathrm{KBr}$ beamsplitter, with $0.5 \mathrm{~cm}^{-1}$ spectral resolution. Necessary modifications of the sample compartment of the spectrometer were done in order to accommodate the cryostat head and allow purging of the instrument by a stream of dry nitrogen to remove water vapors and $\mathrm{CO}_{2}$. A solid sample of MTT was placed in a specially designed doubly thermostattable Knudsen cell [23]. During deposition, both the sample container and valve nozzle compartments of this cell were kept at $323 \mathrm{~K}$. Matrices were prepared by co-deposition of MTT vapors coming out of the Knudsen cell together with large excess of the matrix gas (argon N60, obtained from Air Liquide) onto the CsI substrate of the cryostat cooled to $10 \mathrm{~K}$. Care was taken to keep the guest-to-host ratio in matrices low enough to avoid association. All experiments were performed using an APD Cryogenics closed-cycle helium refrigeration system with a DE-202A expander.

Irradiation of the samples was carried out with a $150 \mathrm{~W}$ xenon arc lamp (Osram XBO $150 \mathrm{~W} / \mathrm{CR}$ OFR). No changes in the spectrum of the matrix-isolated 2MTA were observed during irradiation through a cut-off filter transmitting light above $285 \mathrm{~nm}$. However, irradiation of the matrices through the outer $\mathrm{KBr}$ window of the cryostat $(\lambda>235 \mathrm{~nm})$, resulted in a series of photochemical transformations, as will be described below.

\subsection{Computational methodology}

The quantum chemical calculations for MTT were performed with GAUSSIAN 98 program package [24] at the DFT level of theory, using the $6-311++\mathrm{G}(\mathrm{d}, \mathrm{p})$ basis set and the three-parameter density functional abbreviated as B3LYP, which includes Becke's gradient exchange correction [25] and the Lee, Yang, Parr correlation functional [26]. The calculations on the possible photoproducts were carried out at the same level of theory.

Geometrical parameters of the considered conformations were optimized using the Geometry Direct Inversion of the Invariant Subspace (GDIIS) method [27]. In order to assist the analysis of the experimental spectra, vibrational frequencies and IR intensities were also calculated with the same basis set. The computed harmonic frequencies were scaled down by a single factor $(0.978)$ to correct them for the effects of basis set limitations, neglected part of electron correlation and anharmonicity effects. Normal coordinate analysis was undertaken in the internal coordinates space, as described by Schachtschneider [28], using the program BALGA and the optimized geometries and harmonic force constants resulting from the DFT(B3LYP)/6$311++\mathrm{G}(\mathrm{d}, \mathrm{p})$ calculations.

\section{Results and discussion}

The compound under study can exist in several tautomeric forms, depicted in Fig. 1. The 5-mercapto tautomer (1-methyl-1H-tetrazol-5-thiol) may exist in two different conformers, $\mathrm{A}$ and $\mathrm{B}$, with the $\mathrm{A}$ form, with the methyl group and sulphidryl hydrogen atom oriented to opposite sides, being predicted to be $9.2 \mathrm{~kJ} \mathrm{~mol}^{-1}$ more stable than the $\mathrm{B}$ form. Because of the destabilizing $\mathrm{CH}_{3} \cdots \mathrm{H}(\mathrm{S})$ interaction in conformer $\mathrm{B}$, this form has the thiol hydrogen atom considerably out of the tetrazole-ring plane (the calculated $\mathrm{N}=\mathrm{C}-\mathrm{S}-\mathrm{H}$ dihedral angle is $136.9^{\circ}$ ), whereas in conformer $\mathrm{A}$ this atom is in the ring plane. There are also two 5-thione tautomers, which differ in the position of the tetrazole-ring hydrogen atom. The most stable thione tautomer (1-methyl-1,4-dihydro-5H-tetrazol-5-thione) corresponds to the global minimum of the molecule in the gas phase and is considerably more stable than all other species (the most stable thiol tautomer is the second most stable tautomer and has a relative energy of $32.5 \mathrm{~kJ} \mathrm{~mol}^{-1}$ ). In this tautomer, all atoms are in the same plane, with exception of two methyl hydrogen atoms, which occupy symmetrical positions above and below the molecular plane; the in-plane methyl hydrogen atom points toward $\mathrm{N}(2)$. The second thione tautomer, 1-methyl-1,2-dihydro-5H-tetrazol-5-thione, has an energy higher than that of the global minimum by $104.5 \mathrm{~kJ} \mathrm{~mol}^{-1}$, which results mainly from the additional repulsion between the methyl group and the tetrazole-ring hydrogen atom. Indeed, this repulsion leads to a distortion of the tetrazole-ring from planarity, with pyramidalization of both $\mathrm{N}(1)$ and $\mathrm{N}(2)$ atoms (the $\mathrm{C}(7)-\mathrm{N}(1)-\mathrm{C}(5)-\mathrm{N}(4)$ and $\mathrm{H}-\mathrm{N}(2)-\mathrm{N}(1)-\mathrm{C}(5)$ dihedral angles are -164.1 and $146.3^{\circ}$, respectively), and rotation of the methyl group relatively to the tetrazole-ring (noteworthy this is the only MTT tautomer where the methyl group has one of the hydrogen atoms pointing to a perpendicular direction relatively to the tetrazole ring, instead of pointing to $\mathrm{N}(2)$; in fact, as a whole, the results show that the methyl hydrogen atoms tend to stay as far as possible both from the sulphur atom and the hydrogen atom linked to $\mathrm{N}(2)$ ). Finally, a mesoionic tautomer (1-methyl-1H-tetrazol-3-ium-5-thiolate) does also exist, with relative energy $65.0 \mathrm{~kJ} \mathrm{~mol}^{-1}$. The fully optimized geometries for all tautomers are provided in Appendix (Table S1).

\subsection{IR spectrum of the matrix isolated compound (as-deposited matrix)}

Taking into account the relative stability of all the possible tautomers, only the most stable form (1-methyl-1,4-dihydro$5 H$-tetrazol-5-thione) should be significantly populated in the saturated vapor of the compound used for matrix preparation $(T=323 \mathrm{~K})$. It could then be expected that this would also be the single form present in the as-deposited matrices.

According to the expectations, only the most stable tautomer of MTT was found in the as-deposited argon matrices. This is clearly demonstrated in Fig. 2, by the fairly 

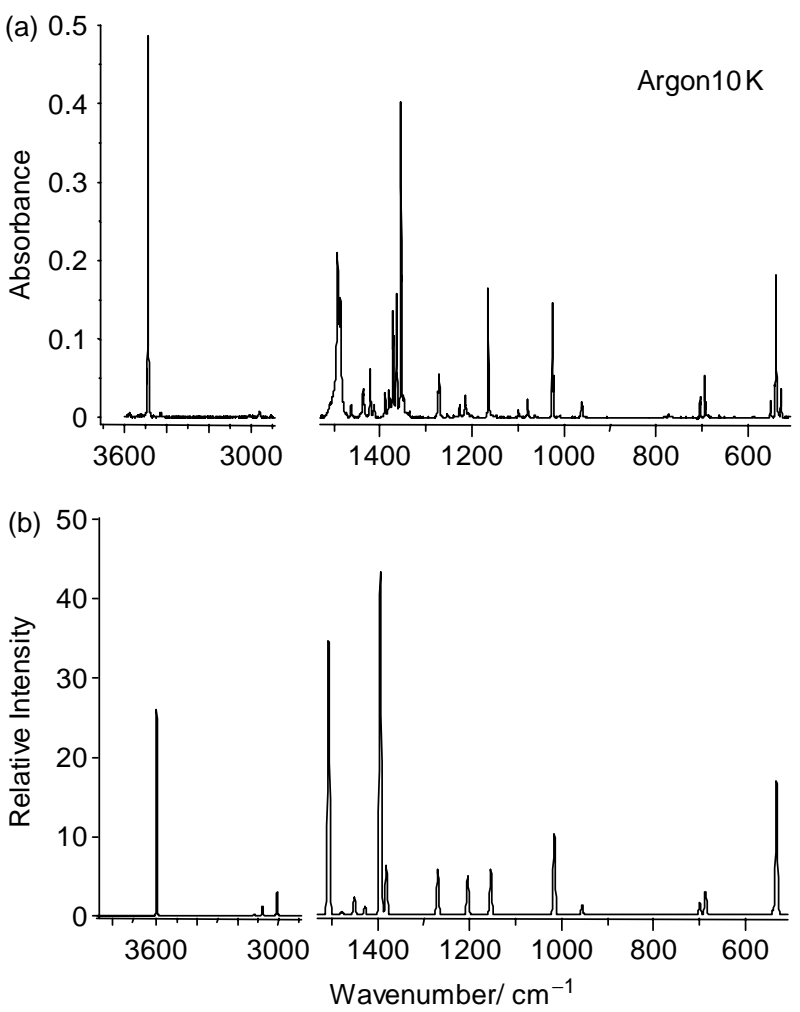

Fig. 2. (a) Infrared spectrum of MTT in argon matrix (substrate temperature $=$ $10 \mathrm{~K}$; nozzle temperature $=323 \mathrm{~K}$ ), and (b) DFT(B3LYP)/6-311++G(d,p) calculated spectrum. The calculated spectrum of MTT (1-methyl-1,4-dihydro$5 \mathrm{H}$-tetrazol-5-thione tautomer) was simulated using GAUSSIAN functions centered at the calculated (scaled) frequency and with bandwidth-at-halfheight equal to $5 \mathrm{~cm}^{-1}$.

good agreement between the observed infrared spectrum of the as-deposited argon matrix of MTT and that calculated at the DFT(B3LYP)/6-311+ $+\mathrm{G}(\mathrm{d}, \mathrm{p})$ level of theory for the 1-methyl-1,4-dihydro-5H-tetrazol-5-thione tautomer. ${ }^{1}$

The proposed band-assignments are given in Table 1. Four intense bands dominate the calculated spectrum: $3578.5(\mathrm{~N}-\mathrm{H}$ stretching; $v \mathrm{~N}-\mathrm{H}), 1498.2(\mathrm{~N}-\mathrm{H}$ in-plane bending; $\delta \mathrm{N}-\mathrm{H})$, $1382.2(\mathrm{~N}=\mathrm{N}$ stretching; $v \mathrm{~N}=\mathrm{N})$ and $516.1(\mathrm{~N}-\mathrm{H}$ out-of-plane rocking; $\gamma \mathrm{N}-\mathrm{H}) \mathrm{cm}^{-1}$. Accordingly, intense features are observed in the spectrum of the as-deposited matrix nearly at these wavenumbers. The features ascribable to the $v \mathrm{~N}-\mathrm{H}, \delta \mathrm{N}-$ $\mathrm{H}$ and $\gamma \mathrm{N}-\mathrm{H}$ modes appear as triplets (at ca. 3485, 1490 and $540 \mathrm{~cm}^{-1}$, respectively), which indicate that the molecules of MTT can occupy at least three different matrix sites. In fact, all vibrations predicted to give rise to strong or medium intensity bands are observed as triplets-see Fig. 2 and Table 1. On the other hand, the band ascribed to $v \mathrm{~N}=\mathrm{N}$ shows six components (between 1380.5 and $1362.6 \mathrm{~cm}^{-1}$ ), probably as a result of the involvement of this vibration in a Fermi resonance interaction with the $v \mathrm{~N}_{1}-\mathrm{N}_{2}+\delta \mathrm{N}-\mathrm{C}\left(\mathrm{H}_{3}\right)$ combination tone, whose

\footnotetext{
${ }^{1}$ Besides the calculated infrared spectrum of 1-methyl-1,4-dihydro- $5 H$ tetrazol-5-thione shown in Fig. 2, the spectra of all the remaining tautomers were also calculated at the same level of theory. The whole set of calculated spectra and results of normal coordinate analyses are provided in Appendix (Tables S2-S8).
}

fundamentals are observed at ca. 960 and $410 \mathrm{~cm}^{-1}$, respectively.

The assignment of the remaining bands could also be made easily, due to the good description of the experimental spectra by the calculations. Three additional points should, however, be noticed: (1) similarly to $v \mathrm{~N}=\mathrm{N}$, the $\delta \mathrm{CH}_{3}$ (methyl symmetric bending) mode does also give rise to a sextet of bands (between 1422.5 and $1411.5 \mathrm{~cm}^{-1}$; see Fig. 2 and Table 1) as a result of a Fermi resonance interaction (in this case involving the $2 v \mathrm{~N}-\mathrm{C}\left(\mathrm{H}_{3}\right)$ overtone); (2) besides being the dominant coordinate contributing to the triplet observed around $1490 \mathrm{~cm}^{-1}$ the $\delta \mathrm{N}-\mathrm{H}$ coordinate also contributes significantly to the normal mode which gives rise to the features observed near $1272 \mathrm{~cm}^{-1}$, ascribed to the $\gamma \mathrm{CH}_{3}^{\prime}$ methyl rocking (according to the normal coordinate analysis results, provided in Appendix (Table S4), the $\delta \mathrm{N}-\mathrm{H}$ coordinate contributes ca. $30 \%$ to the potential energy of this vibration); and (3) the $\nu \mathrm{C}=\mathrm{S}$ stretching mode is predicted to be significantly coupled with one of the tetrazole-ring deformational modes (סring1) and contributing ca. 50\% to the potential energy of the mode observed at $550.8 \mathrm{~cm}^{-1}$ (see Table S4 in Appendix), which is a considerably low wavenumber and indicates that the $\mathrm{C}=\mathrm{S}$ bond in MTT is weaker than a typical $\mathrm{C}=\mathrm{S}$ double bond (in agreement with this result, the $\mathrm{C}=\mathrm{S}$ bond length in MTT, $166 \mathrm{pm}$ - see Table S1 in Appendix, is predicted to be between the observed bond lengths for the $\mathrm{C}=\mathrm{S}$ and $\mathrm{C}-\mathrm{S}$ bonds in dithioesters, which have been found to be ca. 162.5 and 170164 pm long, respectively [29-31]).

\section{2. $U V$-irradiation experiments $(\lambda>235 \mathrm{~nm})$}

As mentioned in Section 1, thermolysis of 5-mercaptotetrazole derivatives in solution has already been described by Awadallah et al. [19]. According to these authors, three main different reaction pathways were observed, yielding (a) methyl isothiocyanate + azide, (b) methyl azide + isothiocyanic acid and (c) molecular sulphur/sulphidric acid+ molecular nitrogen $+N$-methylcarbodiimide. However, because in a matrix the reactions are cage confined, and also because of different properties of the media, e.g. dielectric constant, the situation may be different for the matrix-isolated compound.

In this study, the photochemical processes resulting from in situ broadband UV irradiation $(\lambda>235 \mathrm{~nm})$ of matrixisolated monomeric MTT were probed by FT-IR spectroscopy. The interpretation of the experimental results was supported by extensive DFT calculations of the possible photoproducts and, whenever available, by taking into consideration previously reported spectroscopic data obtained for putative photoproducts.

Fig. 3 shows the spectra $\left(2300-1500 \mathrm{~cm}^{-1}\right.$ region) of the irradiated matrix, obtained after 20 and 100 min of irradiation. Taking into consideration the dependence of the band intensities with time of irradiation, two groups of bands can be easily distinguished, one of them increasing in intensity mostly during the first 20 min of irradiation and decreasing upon prolonged irradiation (group A bands), and the other one, 
Table 1

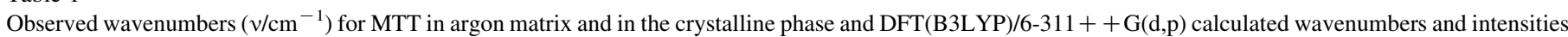
$\left(I / \mathrm{km} \mathrm{mol}^{-1}\right)$ for the most stable tautomer, 1-methyl-1,4-dihydro-5H-tetrazol-5-thione ${ }^{\mathrm{a}}$

\begin{tabular}{|c|c|c|c|c|c|c|}
\hline \multirow{2}{*}{$\begin{array}{l}\text { Approximate } \\
\text { description }\end{array}$} & \multicolumn{2}{|c|}{ Calculated } & \multicolumn{4}{|l|}{ Observed } \\
\hline & $v$ & $\mathrm{I}$ & $v(\mathrm{Ar} ; 10 \mathrm{~K})^{\mathrm{b}}$ & $I$ & $\nu$ (Glass; $275 \mathrm{~K})$ & $I$ \\
\hline$v \mathrm{~N}-\mathrm{H}$ & 3578.5 & 121.2 & $3491.6 / 3487.6 / 3485.3$ & $\mathrm{~m} / \mathrm{S} / \mathrm{sh}$ & $\begin{array}{c}3067.2 / 2857.8 / 2801.6 / \\
2684 / 2657.8\end{array}$ & $\begin{array}{l}\mathrm{S} / \mathrm{S} / \mathrm{S} \\
\mathrm{w} / \mathrm{w}\end{array}$ \\
\hline$v \mathrm{CH}_{3}$ as $^{\prime}$ & 3095.0 & 0.6 & 2995.6 & $\mathrm{w}$ & 2974.7 & S \\
\hline$v \mathrm{CH}_{3}$ as" & 3054.3 & 6.0 & 2961.3 & $\mathrm{w}$ & 2950.5 & $\mathrm{~S}$ \\
\hline$v \mathrm{CH}_{3} \mathrm{~s}$ & 2989.3 & 14.6 & 2907.0 & W & 2919.8 & $\mathrm{~S}$ \\
\hline$\delta \mathrm{N}-\mathrm{H}$ & 1498.2 & 187.9 & $1491.8 / 1488.9 / 1486.0$ & $\mathrm{~S} / \mathrm{sh} / \mathrm{S}$ & $1510.7 / 1488.6$ & $\mathrm{~S} / \mathrm{sh}$ \\
\hline$\delta \mathrm{CH}_{3} \mathrm{as}^{\prime}$ & 1468.2 & 2.4 & 1462.7 & w & 1462.6 & W \\
\hline$\delta \mathrm{CH}_{3}$ as $^{\prime \prime}$ & 1440.9 & 16.4 & $1436.7 / 1435.4 / 1433.8$ & $\mathrm{w} / \mathrm{w} / \mathrm{w}$ & 1434.4 & $\mathrm{w}$ \\
\hline $\begin{array}{l}\mathrm{\delta CH}_{3} \mathrm{~s}[\mathrm{FR} 2 \mathrm{x} v \mathrm{~N}- \\
\left.\mathrm{C}\left(\mathrm{H}_{3}\right)\right]\end{array}$ & 1422.4 & 9.0 & $\begin{array}{c}1422.5 / 1421.2 / 1419.7 / \\
1414.4 / 1313.0 / 1411.5\end{array}$ & $\begin{array}{c}\mathrm{sh} / \mathrm{w} / \mathrm{sh} / \mathrm{w} / \mathrm{w} / \\
\mathrm{w} / \mathrm{w} / \mathrm{w}\end{array}$ & 1413.8 & $\mathrm{w}$ \\
\hline $\begin{array}{l}v \mathrm{~N}=\mathrm{N}\left[\mathrm{FR} v \mathrm{~N}_{1}-\mathrm{N}_{2}+\right. \\
\left.\delta \mathrm{N}-\mathrm{C}\left(\mathrm{H}_{3}\right)\right]\end{array}$ & $1382.2^{\mathrm{c}}$ & 237.0 & $\begin{array}{l}1380.5 / 1376.8 / 1372.0 / \\
1370.4 / 1364.6 / 1362.6\end{array}$ & $\begin{array}{l}\mathrm{w} / \mathrm{w} / \mathrm{m} \\
\mathrm{m} / \mathrm{m} / \mathrm{m}\end{array}$ & $1379.9 / 1355.3$ & $\mathrm{~m} / \mathrm{S}$ \\
\hline$v \mathrm{~N}_{1}-\mathrm{C}_{5}$ & $1369.3^{\mathrm{c}}$ & 60.6 & $1354.2 / 1352.7 / 1348.7$ & $\mathrm{~S} / \mathrm{S} / \mathrm{w}$ & $1351.2 / 1334.8$ & $\mathrm{~S} / \mathrm{S}$ \\
\hline$\gamma \mathrm{CH}_{3}^{\prime}$ & 1263.4 & 44.3 & $1273.5 / 1271.0$ & $\mathrm{~m} / \mathrm{m}$ & 1307.5 & $\mathrm{~S}$ \\
\hline$v \mathrm{~N}_{4}-\mathrm{C}_{5}$ & 1190.4 & 34.9 & $1215.0 / 1213.6 / 1207.7$ & $\mathrm{w} / \mathrm{w} / \mathrm{w}$ & 1214.1 & $\mathrm{w}$ \\
\hline Sring1 & 1149.9 & 29.6 & $1164.5 / 1162.8$ & $\mathrm{~S} / \mathrm{sh}$ & 1166.8 & $\mathrm{~m}$ \\
\hline$\gamma \mathrm{CH}_{3}^{\prime \prime}$ & 1124.7 & 0.1 & 1146.8 & w & 1145.4 & $\mathrm{w}$ \\
\hline$v \mathrm{~N}_{3}-\mathrm{N}_{4}$ & 1045.6 & 0.3 & 1063.4 & w & 1067.6 & $\mathrm{w}$ \\
\hline oring2 & 1015.1 & 47.1 & $1025.5 / 1023.6 / 1022.2$ & $\mathrm{~S} / \mathrm{m} / \mathrm{m}$ & 1044.8 & $\mathrm{~S}$ \\
\hline$v \mathrm{~N}_{1}-\mathrm{N}_{2}$ & 943.6 & 11.4 & 961.8/960.9/959.8 & $\mathrm{w} / \mathrm{sh} / \mathrm{w}$ & 967.7 & W \\
\hline$v \mathrm{~N}-\mathrm{C}\left(\mathrm{H}_{3}\right)$ & 694.7 & 7.8 & $705.1 / 703.8 / 702.8$ & $\mathrm{sh} / \mathrm{w} / \mathrm{w}$ & 704.3 & $\mathrm{~m}$ \\
\hline tring1 & 685.8 & 15.2 & 693.2/691.4 & w/w & $689.7 / 676.6$ & $\mathrm{w} / \mathrm{w}$ \\
\hline$\gamma \mathrm{C}=\mathrm{S}$ & 649.0 & 0.8 & $663.6 / 661.8$ & w/w & 670.1 & w \\
\hline$v \mathrm{C}=\mathrm{S}$ & 540.2 & 3.7 & 550.8 & w & 530.8 & $\mathrm{w}$ \\
\hline$\gamma \mathrm{N}-\mathrm{H}$ & 516.1 & 78.8 & $540.8 / 538.7 / 527.3$ & $\mathrm{~m} / \mathrm{S} / \mathrm{w}$ & $908.7 / 862.2 / 788.4$ & $\mathrm{w} / \mathrm{w} / \mathrm{m}$ \\
\hline$\delta \mathrm{N}-\mathrm{C}\left(\mathrm{H}_{3}\right)$ & 410.5 & 5.4 & 410.1 & W & 424.0 & $\mathrm{~m}$ \\
\hline$\delta \mathrm{C}=\mathrm{S}$ & 220.4 & 4.6 & & & & \\
\hline tring2 & 219.1 & 0.2 & & & & \\
\hline$\gamma \mathrm{N}-\mathrm{C}\left(\mathrm{H}_{3}\right)$ & 190.5 & 9.5 & n.i. & & n.i. & \\
\hline$\tau \mathrm{CH}_{3}$ & 67.8 & 0.0 & $\mid$ & & & \\
\hline
\end{tabular}

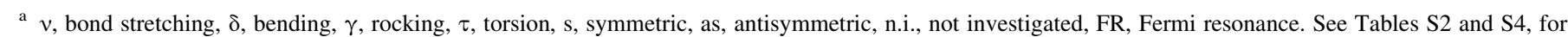

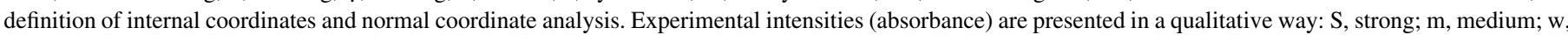
weak, sh, shoulder.

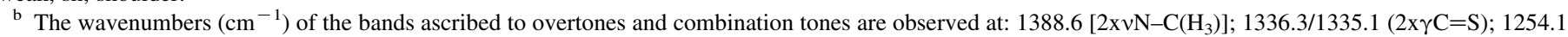
$\left[v \mathrm{~N}-\mathrm{C}\left(\mathrm{H}_{3}\right)+v \mathrm{C}=\mathrm{S}\right] ; 1239.9\left[\nu \mathrm{N}-\mathrm{C}\left(\mathrm{H}_{3}\right)+\gamma \mathrm{N}-\mathrm{H}\right] ; 1226.5(\tau \operatorname{ring} 1+\gamma \mathrm{N}-\mathrm{H}) ; 1098.7(2 \mathrm{x} \gamma \mathrm{C}=\mathrm{S}) ; 1078.7(2 \mathrm{x} \gamma \mathrm{N}-\mathrm{H})$.

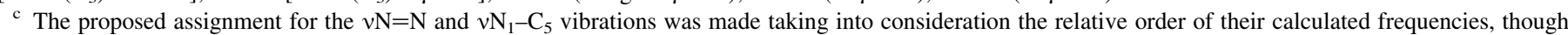
relative intensities would suggest the opposite assignment.

always increasing in intensity (group B). These results indicate that at least two main reaction paths were triggered by irradiation. On the other hand, the bands due to MTT reduce to ca. $60 \%$ of their initial intensity after the first $20 \mathrm{~min}$ of irradiation and to less than $1 \%$ after 100 min of irradiation, indicating that MTT was almost totally converted into other species after 100 min of irradiation. It is also worthmentioning that at the end of the irradiation process, the total intensity of the spectrum was found to be considerably weaker (less than $30 \%$ of the initial total absorbance) than that of the asdeposited matrix. This result suggests that some of the final products absorb only weakly in the infrared or do not absorb at all (among them, $\mathrm{N}_{2}$ and $\mathrm{S}$ are certainly the dominant species).

Fig. 4 shows a scheme of the proposed main reaction paths for photochemical processes initiated by UV irradiation $(\lambda>$ $235 \mathrm{~nm}$ ) of matrix-isolated MTT. The data leading to the identification of these main reaction channels are discussed in detail below.
Most of the product-bands belonging to group B, including the intense structured feature observed at about $2135 \mathrm{~cm}^{-1}$ (see Fig. 3), fit nicely the spectra of methyl isothiocyanate $\left(\mathrm{CH}_{3}-\mathrm{N}=\mathrm{C}=\mathrm{S}\right)$ [32] and $\mathrm{N}$-methylcarbodiimide (Table 2a), which as mentioned above were also found to be produced upon thermolysis of MTT [19].

Methyl isothiocyanate can be obtained by breakage of the $\mathrm{N}_{1}-\mathrm{N}_{2}$ and $\mathrm{N}_{4}-\mathrm{C}_{5}$ bonds in a [2+3] pericyclic ring-opening reaction. The $v \mathrm{~N}=\mathrm{C}=\mathrm{S}$ antisymmetric stretching vibration of this molecule was predicted by the DFT(B3LYP)/6-311++ $\mathrm{G}(\mathrm{d}, \mathrm{p})$ calculations to give rise to a very intense band in the infrared $\left(1175 \mathrm{~km} \mathrm{~mol}^{-1}\right)$ at $2155.4 \mathrm{~cm}^{-1}$, and will contribute to the complex-band with center of gravity at ca. $2135 \mathrm{~cm}^{-1}$. The structured profile of this band fits the band profile reported in the study of matrix-isolated methyl isothiocyanate of Durig et al. [32] fairly well and has been found to be characteristic of isocyanates and isothiocyanates [32-36]. Together with methyl isothiocyanate, production of azide $\left(\mathrm{HN}_{3}\right)$ should occur. 

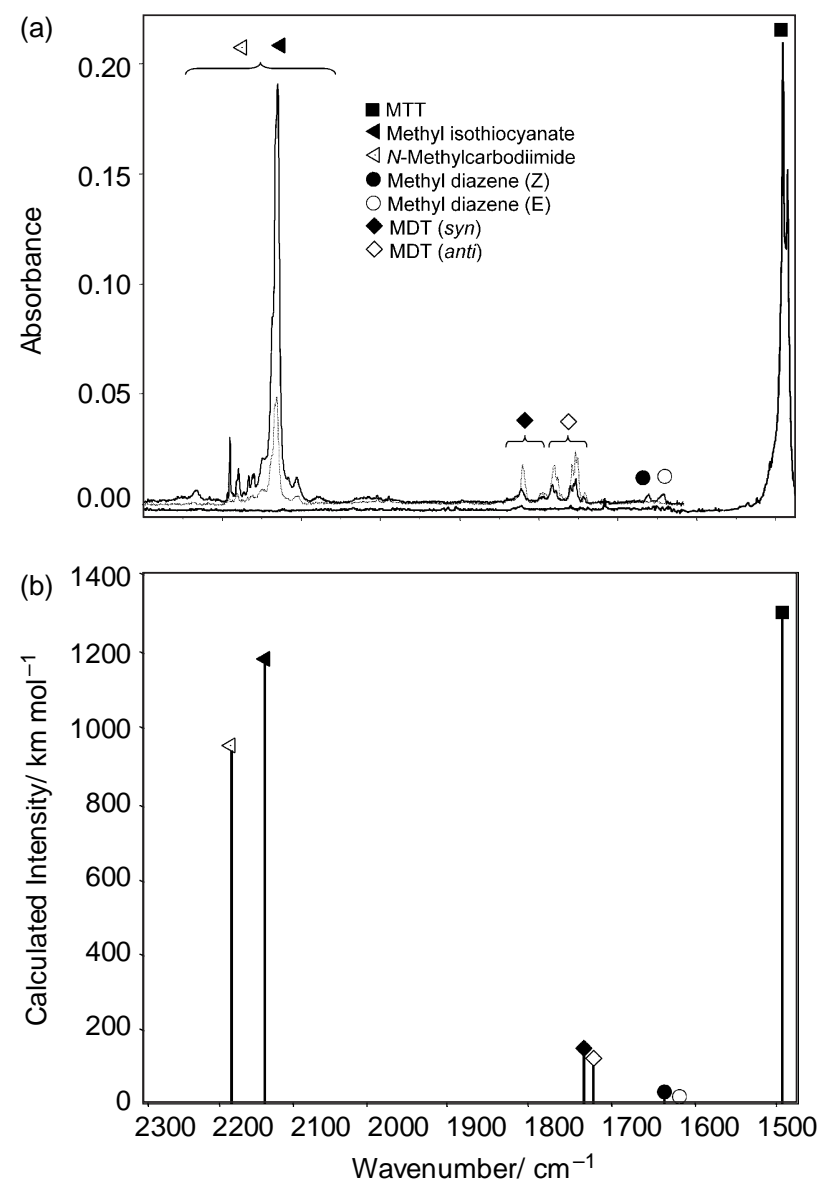

Fig. 3. (a) Infrared spectra $\left(2300-1600 \mathrm{~cm}^{-1}\right.$ region) of the irradiated matrix of MTT, obtained after $20 \mathrm{~min}$ (dotted line) and $100 \mathrm{~min}$ (solid line) of irradiation. The spectrum of the as-deposited matrix in the same spectral region is also presented, the corresponding trace (solid line) being slightly shifted down relatively to the spectra of the irradiated matrix. In the spectra, bands due to traces of water, appearing in the $1550-1650 \mathrm{~cm}^{-1}$ range, were subtracted. (b) Calculated spectra (2300-1500 $\mathrm{cm}^{-1}$ region) for MTT and most of the observed photoproducts (among the identified photoproducts, only CS and HN do not absorb in the spectral region shown in the figure). The calculated spectra are presented as delta functions centered at the calculated (scaled) frequency. The intensity of the calculated band of MTT was multiplied by 7, in order to approximately preserve the relative band intensities in the experimental and calculated spectra shown in the figure.

Identification of this species is complicated by the fact that its most intense band $\left(\nu \mathrm{N}=\mathrm{N}^{+}=\mathrm{N}^{-}\right.$antisymmetric stretching) is expected to lie nearly at the same position as the $v N=C=S$ antisymmetric stretching of methyl isothiocyanate [37] and to have an intrinsic intensity considerably lower than this latter $\left(405 \mathrm{~km} \mathrm{~mol}^{-1}\right.$; DFT(B3LYP)/6-311+ + G(d,p) calculated value). However, the spectrum of matrix-isolated azide is well known [37-41] and the analysis of other regions of the spectra reveals that this species is not present in the irradiated matrix. Indeed, matrix-isolated azide was found to be photochemically labile when subjected to UV-irradiation $\left(\lambda>254 \mathrm{~nm}\right.$ [37]), giving rise to $\mathrm{N}_{2}$ and $\left({ }^{3} \Sigma\right) \mathrm{HN}$. The triplet $\mathrm{HN}$ was reported to give rise to a weak band at ca. $3133 \mathrm{~cm}^{-1}$ in argon matrix [37]. In the spectra of the photolysed matrix, two bands (type B) were observed not far from this frequency (3100 and $3086 \mathrm{~cm}^{-1}$ ). The higher frequency band exhibits the relatively broad profile expected for a small size species like $\mathrm{NH}$, which will be partially rotating in the matrix (on the other hand, the lower frequency band is sharp and is ascribable to a combination mode of $N$-methylcarbodiimide, as discussed below). Hence, the results suggest that the azide initially formed together with methyl isothiocyanate quickly reacts to form $\mathrm{N}_{2}$ and triplet $\mathrm{HN}$.

$\mathrm{N}$-methylcarbodiimide production occurs simultaneously with expulsion of both molecular nitrogen and sulphur, which are not expected to give rise to any observable IR band. From the 16 vibrations of $N$-methylcarbodiimide predicted to occur in the studied spectral region, all but the very low intensity $\gamma \mathrm{CH}_{3}^{\prime \prime}$ rocking mode were observed in the spectra of the irradiated matrix (see Table $2 \mathrm{~b}$ ). The calculations predict the most intense bands of $N$-methylcarbodiimide, corresponding to the $v \mathrm{~N}=\mathrm{C}=\mathrm{N}$ antisymmetric stretching and $\delta \mathrm{N}-\mathrm{H}$ in plane bending modes, at $2191.9 \mathrm{~cm}^{-1}$ (with intensity $\left.953.1 \mathrm{~km} \mathrm{~mol}^{-1}\right)$ and $919.9 \mathrm{~cm}^{-1}\left(245.0 \mathrm{~km} \mathrm{~mol}^{-1}\right)$, respectively. The $\delta \mathrm{N}-\mathrm{H}$ vibration is assigned to a multiplet of bands appearing in the $890-950 \mathrm{~cm}^{-1}$ spectral range. The multiplet structure of the band clearly reveals that the molecule is produced in a variety of sites whose specificity seems to affect considerably the vibrations mostly localized in the $\mathrm{NH}$ group. Indeed, the less intense $\gamma \mathrm{N}-\mathrm{H}$ out of plane mode was also found to give rise to a structured band (with two main components at 587.1 and $588.8 \mathrm{~cm}^{-1}$; see Table $2 \mathrm{~b}$ ) and the $v \mathrm{~N}-\mathrm{H}$ stretching mode to a broadband around $3400 \mathrm{~cm}^{-1}$, which can also result from unresolved superposition of a series of bands with slightly different frequencies. On the other hand, with all probability, the $v \mathrm{~N}=\mathrm{C}=\mathrm{N}$ antisymmetric stretching mode contributes to the experimentally observed complex feature with gravity center at ca. $2135 \mathrm{~cm}^{-1}$, also due to the $v \mathrm{~N}=\mathrm{C}=\mathrm{S}$ antisymmetric stretching of methyl isothiocyanate.

The bands belonging to group A are, in general, more structured than those belonging to group B, clearly indicating that the species which originate them are produced in multiple sites and, probably, interacting considerably with other species present in the matrix cage. In order to identify the products that give rise to the observed A-type bands, extensive calculations of the IR spectrum of putative candidates were undertaken. The series of molecules considered is listed in Table S9, provided in Appendix. An essential criterion the putative photoproduced species should obey was to give rise to significantly intense bands in the $1720-1820 \mathrm{~cm}^{-1}$ spectral range, where the most intense A-type bands are observed. Apart from diazomethyl radical (HCNN), which also exhibits bands in this region [42] but whose production looks very improbable, only 1-methyl$1 H$-diazirene-3-thiol (MDT) was found to satisfy this criterion. MDT can be obtained from MTT by nitrogen elimination followed by $\mathrm{H}-1,3$ migration from the nitrogen $\mathrm{N}(4)$ to the sulphur atom and ring-closure, and may exist in two conformers. One of the conformers has the SH group anti relatively to the methyl group, whereas the second form has these groups syn; see Fig. 4. The two conformers of MDT are predicted by the calculations to have very close energies (the anti form is $1.34 \mathrm{~kJ} \mathrm{~mol}^{-1}$ more stable than the syn form, as predicted by the DFT(B3LYP)/6-311+ $+\mathrm{G}(\mathrm{d}, \mathrm{p})$ calculations) 


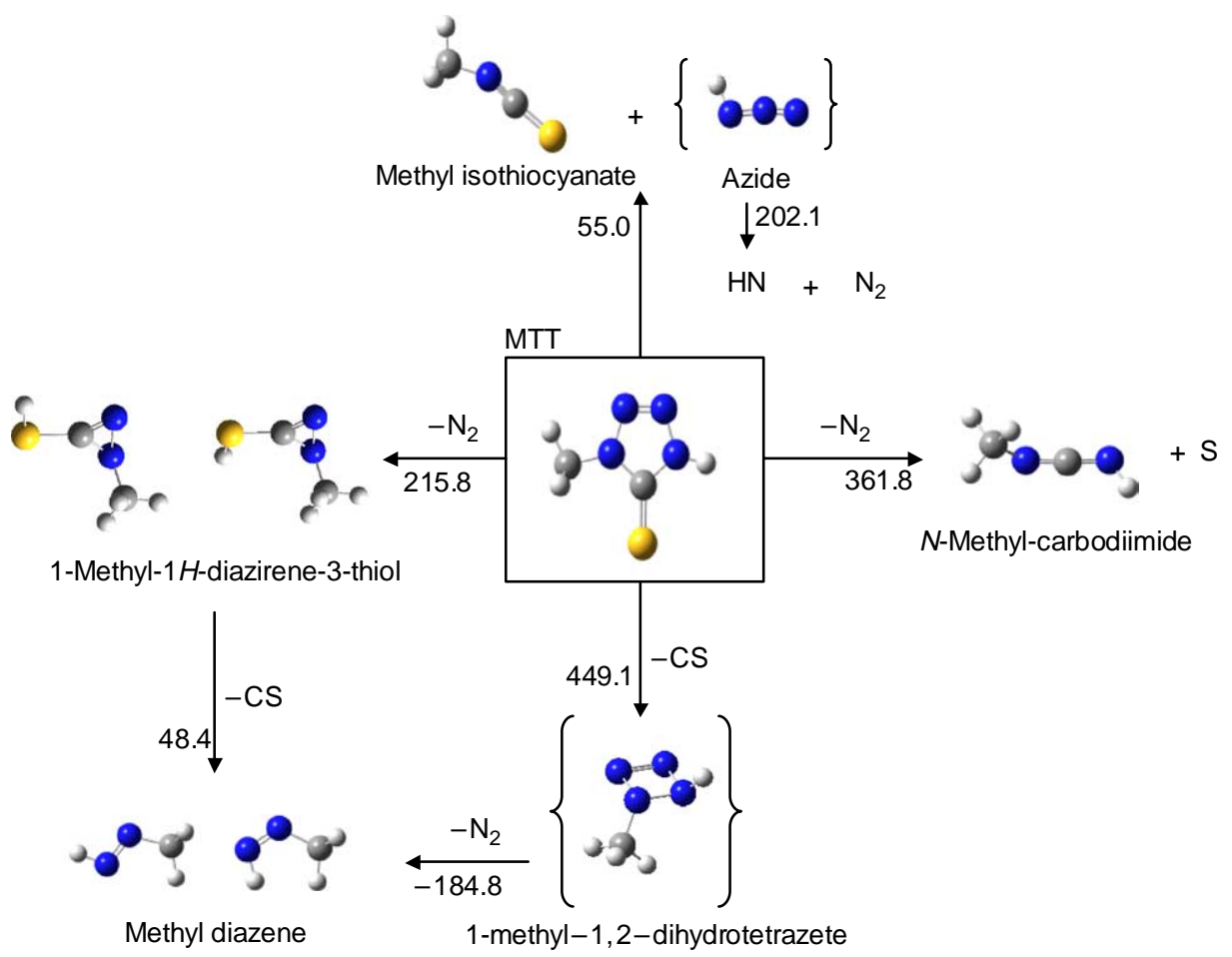

Fig. 4. Proposed pathways for reactions resulting from irradiation $(\lambda>235 \mathrm{~nm})$ of MTT monomer in argon matrix. Note that no bands due to 1 -methyl1,2-dihydrotetrazete and azide were identified experimentally; the relevance of these two species is discussed in the text. Zero-point corrected energy differences $\left(\mathrm{kJ} \mathrm{mol}^{-1}\right)$ between products and reactants for each process are given in the figure. In cases where more than one conformer exist, energies relate to reactions involving the most stable conformers.

and, with all probability, both are present in the photolysed matrix (see Table 2c for assignments).

Upon prolonged irradiation, MDT undergoes secondary photoreactions, reducing its concentration in the matrix. Since no new bands appear in the spectra together with disappearance of the bands due to this species, it shall be converted in weakly absorbing species. Indeed, MDT can further react to give rise to methyl diazene $\left(\mathrm{CH}_{3} \mathrm{~N}=\mathrm{NH}\right)$ plus $\mathrm{CS}$. Methyl diazene may also exist in two conformers ( $\mathrm{Z}$ and $\mathrm{E}$ isomers), and contribute to the bands observed at 1656/1639,1457, 1433, 1395, 1110 and $846 / 842 \mathrm{~cm}^{-1}$ (Z/E isomers, respectively), which are predicted by the calculations to occur at 1642/1623, 1457 (in both $\mathrm{Z}$ and $\mathrm{E}$ isomers), 1437, 1377/1376, 1119/1120 and $851 / 845 \mathrm{~cm}^{-1}$; Table $2 \mathrm{~d}$. The presence of CS in the photolysed matrix manifests itself as the complex band lying in the 1257$1243 \mathrm{~cm}^{-1}$ range (in the gaseous phase it was observed at

Table 2a

Observed and calculated IR bands of methyl isothiocyanate

\begin{tabular}{|c|c|c|c|c|}
\hline \multirow[t]{2}{*}{ Observed frequency $\left(\mathrm{cm}^{-1}\right)$} & \multirow{2}{*}{$\begin{array}{l}\text { Literature frequency }\left(\mathrm{cm}^{-1}\right) \\
{[32]}\end{array}$} & \multicolumn{2}{|c|}{ Calculated [B3LYP/6-311+ + G(d,p)] } & \multirow[t]{2}{*}{ Approximate description } \\
\hline & & Frequency $\left(\mathrm{cm}^{-1}\right)$ & Intensity $\left(\mathrm{km} \mathrm{mol}^{-1}\right)$ & \\
\hline 661.5 & 661 & 659.2 & 24.0 & $\nu \mathrm{CN}$ \\
\hline n.o. & 1109 & 1098.7 & $<0.1$ & $\gamma \mathrm{CH}_{3}^{\prime \prime}$ \\
\hline n.o. & 1142 (gas) & 1148.4 & 5.3 & $\gamma \mathrm{CH}_{3}^{\prime}$ \\
\hline 1422.3 & 1421 & 1420.8 & 66.6 & $\mathrm{\delta CH}_{3} \mathrm{sym}$ \\
\hline 2079.3 & 2085 & & & $\nu \mathrm{CN}+\delta \mathrm{CH}_{3} \mathrm{sym}$ \\
\hline${ }^{\mathrm{a}}$ & $2118 / 2126$ & 2155.4 & 1175.3 & $v$ NCS asym \\
\hline 2215.9 & $2211 / 2217$ & & & $2 \mathrm{x} v \mathrm{NCS}$ sym FR $v$ NCS asym \\
\hline $2233.4 / 2252.9$ & $2236 / 2256$ & & & $\delta \mathrm{CNC}+v \mathrm{NCS}$ asym \\
\hline 2801.5 & 2791 & & & $v \mathrm{NCS}$ asym $+v \mathrm{CN}$ \\
\hline n.o. & 2818 & & & $2 \mathrm{x} \delta \mathrm{CH}_{3} \mathrm{sym}$ \\
\hline
\end{tabular}

\footnotetext{
${ }^{\text {a }}$ Very strong and complex multiplet between 2105 and $2193 \mathrm{~cm}^{-1}$ (superimposed with the $v \mathrm{NCN}$ asym band of $N$-methylcarbodiimide; see text).
} 
Table $2 b$

Observed and calculated IR bands of $N$-methylcarbodiimide

\begin{tabular}{|c|c|c|c|}
\hline \multirow[t]{2}{*}{ Observed frequency $\left(\mathrm{cm}^{-1}\right)$} & \multicolumn{2}{|c|}{ Calculated [B3LYP/6-311++G(d,p)] } & \multirow[t]{2}{*}{ Approximate description } \\
\hline & Frequency $\left(\mathrm{cm}^{-1}\right)$ & Intensity $\left(\mathrm{km} \mathrm{mol}^{-1}\right)$ & \\
\hline $587.1 / 588.8$ & 558.9 & 72.8 & $\gamma \mathrm{N}-\mathrm{H}$ \\
\hline 627.7 & 626.9 & 18.4 & $\delta N C N$ \\
\hline 853.4 & 870.0 & 24.0 & $v \mathrm{NC}\left(\mathrm{H}_{3}\right)$ \\
\hline 891.5/903.0/934.1/938.8/940.9/951.3 & 919.9 & 245.0 & $\delta \mathrm{N}-\mathrm{H}$ \\
\hline 1110.4 & 1111.9 & 9.1 & $\gamma \mathrm{CH}_{3}^{\prime}$ \\
\hline n.o. & 1113.7 & 1.0 & $\gamma \mathrm{CH}_{3}^{\prime \prime}$ \\
\hline 1391.7 & 1368.4 & 10.5 & $v \mathrm{NCN}$ sym \\
\hline 1424.9 & 1425.3 & 22.8 & $\delta \mathrm{CH}_{3} \mathrm{sym}$ \\
\hline 1456.8 & 1457.9 & 7.2 & $\delta \mathrm{CH}_{3}$ asym $^{\prime \prime}$ \\
\hline 1470.6 & 1473.6 & 16.2 & $\delta \mathrm{CH}_{3}$ asym $^{\prime}$ \\
\hline$-^{\mathrm{a}}$ & 2191.9 & 953.1 & $v \mathrm{NCN}$ asym \\
\hline 2953.2 & 2955.3 & 61.2 & $v \mathrm{CH}_{3} \mathrm{sym}$ \\
\hline 3029.0 & 3024.0 & 23.1 & $v \mathrm{CH}_{3} \mathrm{asym}^{\prime}$ \\
\hline 3029.0 & 3030.4 & 17.4 & $v \mathrm{CH}_{3}$ asym $^{\prime \prime}$ \\
\hline 3085.7 & & & $v \mathrm{NCN}$ asym $+\delta \mathrm{N}-\mathrm{H}$ \\
\hline$\sim 3400$ & 3496.9 & 62.3 & $v \mathrm{~N}-\mathrm{H}$ \\
\hline
\end{tabular}

${ }^{a}$ Very strong and complex multiplet between 2105 and $2193 \mathrm{~cm}^{-1}$ (superimposed with the $v$ NCS asym band of methyl isothiocyanate; see text).

$1272 \mathrm{~cm}^{-1}$ [43]). Note that methyl diazene and CS (plus $\mathrm{N}_{2}$ ) are also the expected photoproducts resulting from direct $\mathrm{CS}$ elimination from MTT (eventually implying formation of the unstable 1-methyl-1,2-dihydrotetrazete intermediate, which was not observed spectroscopically; see Fig. 4).

In summary, in situ UV-irradiation $(\lambda>235 \mathrm{~nm})$ of the matrix-isolated monomer of MTT is shown to trigger different photochemical processes, all of them involving cleavage of the tetrazole ring: e.g. (1) loss of nitrogen, with production of 1-methyl-1H-diazirene-3-thiol, which is produced in two different conformers; (2) ring cleavage leading to production of methyl isothiocyanate and azide; (3) simultaneous elimination of nitrogen and sulphur with production of $\mathrm{N}$-methylcarbodiimide and, eventually, (4) CS elimination, leading to methyl diazene, $\mathrm{CS}$ and $\mathrm{N}_{2}$ Following these photoprocesses, subsequent reactions occur, with production of methyl diazene, carbon monosulphide and triplet nitrogen hydride. We have also investigated the possibility of occurrence of the third previously observed thermal channel [19], which leads to formation of methylazide and isothiocyanic acid. Our data, however, do not show any clear evidence of presence of these two species in the irradiated matrices.

Table 2c

Observed and calculated IR bands of 1-methyl-1H-diazirene-3-thiol (MDT)

\begin{tabular}{|c|c|c|c|c|}
\hline \multirow[t]{2}{*}{ Observed frequency $\left(\mathrm{cm}^{-1}\right)$} & \multicolumn{2}{|c|}{ Calculated $[\mathrm{B} 3 \mathrm{LYP} / 6-311++\mathrm{G}(\mathrm{d}, \mathrm{p})]$} & \multirow[t]{2}{*}{ Approximate description } & \multirow[t]{2}{*}{ Conformer } \\
\hline & Frequency $\left(\mathrm{cm}^{-1}\right)$ & Intensity $\left(\mathrm{km} \mathrm{mol}^{-1}\right)$ & & \\
\hline$\sim 565$ & $565.8,560.2$ & $5.1,4.4$ & $\gamma \mathrm{C}-\mathrm{S}$ & syn, anti \\
\hline 640.6 & 622.4 & 22.6 & $v \mathrm{C}-\mathrm{S}$ & syn \\
\hline $666.8 / 671.1 / 672.5 / 679.2$ & 625.3 & 24.1 & $v \mathrm{C}-\mathrm{S}$ & anti \\
\hline 786.2 & 843.1 & 26.8 & $\delta \mathrm{CSH}$ & anti \\
\hline 789.1 & 868.6 & 26.5 & $\delta \mathrm{CSH}$ & syn \\
\hline 866.8 & 949.8 & 10.4 & $v \mathrm{~N}-\mathrm{C}\left(\mathrm{H}_{3}\right)$ & syn \\
\hline 868.4 & 952.8 & 7.8 & $v \mathrm{~N}-\mathrm{C}\left(\mathrm{H}_{3}\right)$ & anti \\
\hline n.o. & $1080.5,1180.3$ & $1.0,1.3$ & $\gamma \mathrm{CH}_{3}^{\prime \prime}$ & syn, anti \\
\hline 1080.5 & $1118.2,1119.8$ & $3.2,4.3$ & $\gamma \mathrm{CH}_{3}^{\prime}$ & syn, anti \\
\hline $\begin{array}{l}\text { 1101.4/1102.9/1104.4/1105.7/ } \\
1118.3 / 1121.3 / 1124.0 / 1131.3\end{array}$ & 1229.4 & 31.9 & $v \mathrm{CN}$ & syn \\
\hline $\begin{array}{l}1153.6 / 1156.4 / 1171.2 / 1173.4 / \\
1175.8\end{array}$ & 1241.6 & 48.2 & $v \mathrm{CN}$ & anti \\
\hline 1408.2 & $1399.2,1398.3$ & $4.5,3.5$ & $\delta \mathrm{CH}_{3} \mathrm{sym}$ & syn, anti \\
\hline 1442.1 & $1436.8,1436.1$ & $4.5,4.6$ & $\delta \mathrm{CH}_{3}$ asym $^{\prime}$ & syn, anti \\
\hline 1461.6 & $1464.4,1464.9$ & $12.3,12.0$ & $\delta \mathrm{CH}_{3}$ asym $^{\prime \prime}$ & syn, anti \\
\hline $\begin{array}{l}1749.4 / 1752.5 / 1756.1 / 1757.2 / \\
1770.1 / 1774.9 / 1779.1\end{array}$ & 1734.7 & 127.3 & $v \mathrm{C}=\mathrm{N}$ & syn \\
\hline 1792.1/1794.0/1817.9/1819.1 & 1746.9 & 142.3 & $v \mathrm{C}=\mathrm{N}$ & anti \\
\hline n.o. & $2603.8,2591.1$ & $0.2,0.4$ & $v \mathrm{~S}-\mathrm{H}$ & syn, anti \\
\hline 2928.4 & $2937.5,2937.6$ & $29.9,29.8$ & $v \mathrm{CH}_{3}$ sym & syn, anti \\
\hline 2971.4 & $3001.2,3002.0$ & $18.3,16.4$ & $v \mathrm{CH}_{3}$ asym $^{\prime \prime}$ & syn, anti \\
\hline 3029.0 & $3042.0,3043.0$ & $15.8,17.1$ & $v \mathrm{CH}_{3}$ asym $^{\prime}$ & syn, anti \\
\hline
\end{tabular}


Table $2 d$

Observed and calculated IR bands of methyl diazene

\begin{tabular}{|c|c|c|c|c|}
\hline \multirow[t]{2}{*}{ Observed frequency $\left(\mathrm{cm}^{-1}\right)$} & \multicolumn{2}{|c|}{$\underline{\text { Calculated [B3LYP/6-311+ + G(d,p)] }}$} & \multirow[t]{2}{*}{ Approximate description } & \multirow[t]{2}{*}{ Conformer } \\
\hline & Frequency $\left(\mathrm{cm}^{-1}\right)$ & Intensity $\left(\mathrm{km} \mathrm{mol}^{-1}\right)$ & & \\
\hline 583.5 & 544.0 & 16.9 & $\delta \mathrm{CNN}$ & $\mathrm{E}$ \\
\hline n.o. & 564.6 & 1.2 & $\delta \mathrm{CNN}$ & $\mathrm{Z}$ \\
\hline 842.0 & 845.4 & 34.1 & $\gamma \mathrm{N}-\mathrm{H} \mathrm{E}$ & \\
\hline 845.9 & 851.0 & 43.7 & $\gamma \mathrm{N}-\mathrm{H}$ & $\mathrm{Z}$ \\
\hline n.o. & 885.0 & 6.7 & $v \mathrm{CN}$ & $\mathrm{Z}$ \\
\hline 903.0 & 909.6 & 13.6 & $v \mathrm{CN}$ & $\mathrm{E}$ \\
\hline 1110.4 & $1119.6,1119.1$ & $8.6,3.4$ & $\gamma \mathrm{CH}_{3}^{\prime}$ & $\mathrm{E}, \mathrm{Z}$ \\
\hline n.o. & 1130.3 & 8.2 & $\gamma \mathrm{CH}_{3}^{\prime \prime}$ & $\mathrm{Z}$ \\
\hline 1142.1 & 1145.7 & 20.3 & $\gamma \mathrm{CH}_{3}^{\prime \prime}$ & $\mathrm{E}$ \\
\hline 1395.5 & $1376.2,1376.8$ & $7.8,11.8$ & $\delta \mathrm{CH}_{3}$ sym & $\mathrm{E}, \mathrm{Z}$ \\
\hline n.o. & 1422.7 & 8.0 & $\delta \mathrm{CH}_{3}$ asym $^{\prime \prime}$ & $\mathrm{Z}$ \\
\hline n.o. & 1428.4 & 4.4 & $\delta \mathrm{CH}_{3} \operatorname{asym}^{\prime}$ & $\mathrm{Z}$ \\
\hline 1432.9 & 1436.6 & 16.4 & $\delta \mathrm{CH}_{3}$ asym $^{\prime}$ & $\mathrm{E}$ \\
\hline 1432.9 & 1436.7 & 12.2 & $\delta \mathrm{CH}_{3}$ asym $^{\prime \prime}$ & $\mathrm{E}$ \\
\hline 1456.8 & $1456.7,1456.8$ & $22.1,77.3$ & $\delta \mathrm{NH}$ & $\mathrm{E}, \mathrm{Z}$ \\
\hline 1639.2 & 1623.0 & 5.6 & $v \mathrm{~N}=\mathrm{N}$ & $\mathrm{E}$ \\
\hline 1656.4 & 1642.3 & 29.8 & $v \mathrm{~N}=\mathrm{N}$ & $\mathrm{Z}$ \\
\hline 2898.3 & 2899.6 & 37.5 & $v \mathrm{CH}_{3}$ sym & Z \\
\hline 2953.2 & 2948.9 & 16.2 & $v \mathrm{CH}_{3}$ sym & $\mathrm{E}$ \\
\hline 2953.2 & 2950.5 & 99.7 & $v \mathrm{~N}-\mathrm{H}$ & $\mathrm{Z}$ \\
\hline 3029.0 & $3027.6,3015.4$ & $8.8,10.9$ & $v \mathrm{CH}_{3}$ asym $^{\prime}$ & E, Z \\
\hline 3029.0 & $3037.3,3036.2$ & $15.0,5.6$ & $v \mathrm{CH}_{3}$ asym $^{\prime \prime}$ & $\mathrm{E}, \mathrm{Z}$ \\
\hline n.o. & 3206.8 & 12.3 & $v \mathrm{~N}-\mathrm{H}$ & $\mathrm{E}$ \\
\hline
\end{tabular}

\subsection{IR spectrum of MTT in the low temperature neat solid state}

Fig. 5 shows the spectrum of the low temperature crystalline phase obtained by deposition of the vapor of MTT onto the cold substrate of the cryostat (at $10 \mathrm{~K}$ ) followed by slow annealing of the solid film. Crystallization was found to start at a temperature of ca. $150 \mathrm{~K}$.
The first conclusion that can be extracted from the spectra shown in Fig. 5 is that, as it was found in the gaseous phase and for the matrix-isolated compound, in the neat crystalline phase also MTT exists exclusively as the thione tautomer. Indeed, the correlation between the observed spectrum for the crystal and the calculated for the thione tautomer of MTT is evident from the data shown in Fig. 5.

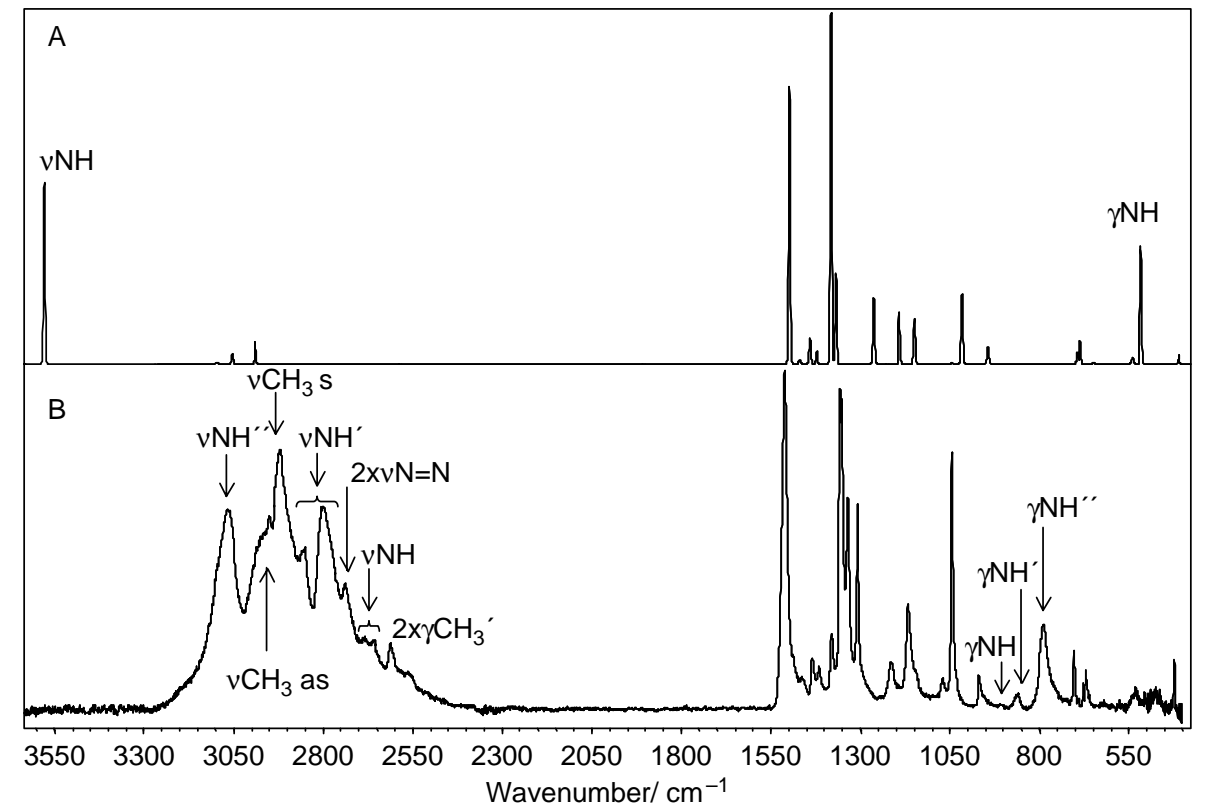

Fig. 5. (A) Infrared spectrum of crystalline MTT (as film; $T=275$ K). (B) DFT(B3LYP)/6-311 + + G(d,p) calculated spectrum for the monomer MTT (1-methyl-1,4dihydro-5H-tetrazol-5-thione tautomer). The calculated spectrum was simulated using Gaussian functions centered at the calculated (scaled) frequency and with bandwidth-at-half-height equal to $5 \mathrm{~cm}^{-1}$. 
Naturally, as it could be anticipated, the main differences between the calculated MTT spectrum (and that of the matrixisolated compound) and the observed spectrum of the crystal can be easily identified as occurring for bands ascribable to vibrations of the NH group, which in the crystal is involved in hydrogen bonding interactions. According to Rozenberg et al. $[44,45]$, for nearly linear H-bonds, the red shift of the $v \mathrm{NH}$ stretching mode, $v_{1}$, and the blue shift of the corresponding out-of-the-plane $\gamma \mathrm{NH}$ rocking mode, $v_{4}$, which occur upon $\mathrm{H}$-bond formation, may be empirically correlated, because both parameters correlate with the H-bond enthalpy $(\Delta H)$

$\Delta \nu_{4}^{2}\left(\mathrm{~cm}^{-2}\right)=2.5\left(\Delta \nu_{1}\left(\mathrm{~cm}^{-1}\right)^{1 / 2}-18\right.$

$(\Delta H)^{2}=1.92\left[\left(\Delta \nu_{1}\right)-40\right]$

$-\Delta H=0.67 \Delta \nu_{4}^{2}$

where $\Delta \nu_{4}^{2}=\left(10^{-2} \nu_{4}^{\mathrm{H}}\right)^{2}-\left(10^{-2} \nu_{4}^{0}\right)^{2}$ and $\Delta \nu_{1}=\nu_{1}^{\mathrm{H}}-\nu_{1}^{0}$, and the superscripts ' $\mathrm{H}$ ' and ' 0 ' pertain to $\mathrm{H}$-bonded and free molecules, respectively.

In general, for crystals with natural isotopic content, the $v \mathrm{NH}$ stretching spectral region is considerably complex, owing to extensive vibrational coupling between the $v \mathrm{NH}$ modes and low frequency vibrations, presence of overtones and combination tones and Fermi resonance interactions. This fact makes the bands corresponding to the $v \mathrm{NH}$ stretching mode difficult to assign with certainty. However, using the correlation (1) it is possible to estimate the position of these bands in the spectrum of the crystal from the position of the bands ascribed to the $v \mathrm{NH}$ rocking mode, which can be easily observed in the $1000-700 \mathrm{~cm}^{-1}$ region. Indeed, a very important property exhibited by $v_{4}$ is that, in contrast to $v_{1}$, it gives rise to bands that do not change their molar integral intensity with the H-bond energy and thus they remain narrow and well resolved independently of the strength of the H-bond interaction $[44,45]$. Consequently, $v_{4}$ can be used for a direct quantitative estimation of the relative abundance of different $\mathrm{H}$-bonds in a given crystal. On the other hand, as mentioned above, the peak positions of the bands due to both $v_{1}$ and $v_{4}$ are sensitive to the $\mathrm{H}$-bond energy and can be used to estimate this property on the basis of the empirical quantitative relationships (2) and (3) $[44,45]$.

Three bands are observed in the $1000-700 \mathrm{~cm}^{-1}$ region of the spectrum of crystalline MTT that do not have counterpart in both the calculated spectrum and that of the matrix-isolated monomer: $788.4,862.2$ and $908.7 \mathrm{~cm}^{-1}$ (see Fig. 5). According to Rozenberg et al. [44,45], this means that three different kinds of H-bonds, with different strengths, are present in the sample. Using the empirical correlation (1), the frequencies corresponding to the $v \mathrm{NH}$ stretching modes associated with each one of the three types of H-bonds in crystalline MTT can be estimated as 3069,2846 and $2675 \mathrm{~cm}^{-1}$. Accordingly, bands at 3067.2, 2857.8/2801.6 (average frequency $2829.7 \mathrm{~cm}^{-1}$ ) and 2684/2657.8 (average frequency $2671.3 \mathrm{~cm}^{-1}$ ) are observed experimentally and then ascribed to the $v \mathrm{NH}$ stretching vibration in the three differently H-bonded NH groups (Fig. 5).

On the other hand, as mentioned above, the relative intensities of the $v_{4}$ bands correlate with the relative abundance of a given type of $\mathrm{H}$-bond [44,45], whose energies can be calculated by using either relationship (2) or (3). Then, the results indicate that $86.9 \%$ of the $\mathrm{H}$-bonds in the MTT crystalline sample have an enthalpy of $-24.61 \mathrm{~kJ} \mathrm{~mol}^{-1}$, $11.5 \%$ an enthalpy of $-32.40 \mathrm{~kJ} \mathrm{~mol}^{-1}$ and $1.6 \%$ an enthalpy of $-37.24 \mathrm{~kJ} \mathrm{~mol}^{-1}$. The enthalpy values presented correspond to mean values obtained using Eqs. (2) and (3) above, and correlate with the $788.4 / 3067.2 \mathrm{~cm}^{-1}, 862.2 / 2829.7 \mathrm{~cm}^{-1}$ and $908.7 / 2671.3 \mathrm{~cm}^{-1} v_{4} / v_{1}$ bands, respectively. Without knowledge of the crystal structure of MTT, an unequivocal interpretation cannot be given for the presence of the three different kinds of $\mathrm{H}$-bonds in the crystal. Taking into consideration the estimated percentages indicated above, the less abundant type of $\mathrm{H}$-bonds result with all probability from crystal defects. However, it is important to point out that the reliability of the empirical correlations here used has been tested exhaustively for a large number of different crystals with different types of H-bond networks, with excellent results [4446], without any doubt the characteristic ordered H-bonds in the MTT crystal are of at least two different types.

The assignment of the remaining bands observed in the spectrum of the crystal is straightforward and is presented in Table 1.

\section{Conclusions}

The DFT(B3LYP)/6-311+ + G(d,p) calculations predict that in the gaseous phase MTT should exist almost exclusively as the thione tautomer. Accordingly, this was the only tautomer of MTT observed for the compound isolated in a low temperature argon matrix, as well as in the case of the neat crystalline phase. Rozenberg's [44,45] empirical correlation between the frequencies of the stretching and out-of-the-plane rocking modes originated in $\mathrm{H}$-bonded $\mathrm{NH}$ groups was used to characterize the H-bonding scheme in crystalline MTT, allowing the conclusion to be drawn that three different types of $\mathrm{H}$-bonds are present in the crystal, with energies of -24.61 , -32.40 and $-37.24 \mathrm{~kJ} \mathrm{~mol}^{-1}$.

Irradiation $(\lambda>235 \mathrm{~nm})$ of the matrix-isolated monomer of MTT leads to observation of several photochemical processes. Three dominant reaction pathways were identified: (1) loss of nitrogen, with production of 1-methyl- $1 H$-diazirene-3-thiol (two different conformers); (2) ring cleavage leading to production of methyl isothiocyanate and azide; (3) simultaneous elimination of nitrogen and sulphur with production of $\mathrm{N}$-methylcarbodiimide. Following these photoprocesses, subsequent reactions occur, with production of methyl diazene, carbon monosulphide and nitrogen hydride. The possibility of occurrence of direct elimination of CS from the MTT molecule upon irradiation, leading to methyl diazene, $\mathrm{CS}$ and $\mathrm{N}_{2}$, cannot also be excluded. 


\section{Acknowledgements}

The authors acknowledge the Portuguese Science Foundation (FCT-POCTI/QUI/59019/2004) and FEDER for financial support. A.G.-Z. thanks FCT (Grant SFRH/BPD/11499/2002), CONICET and the Argentinian Agencia Nacional de Promoción Científica y Tecnológica (PICT 13080). I.D.R. acknowledges FCT for the Grant SFRH/BPD/1661/2000.

\section{Supplementary data (Appendix)}

Supplementary data associated with this article can be found, in the online version, at doi:10.1016/j.molstruc.2005.08.019

\section{References}

[1] H. Singh, A. Chawla, V. Kapoor, D. Paul, R. Malhotra, Prog. Med. Chem. 17 (1980) 151.

[2] G. Sandmann, C. Schneider, P. Boger, Z. Naturforsch. C 51 (1996) 534.

[3] J. Buynak, V. Doppalapudi, A. Rao, S. Nidamarthy, G. Adam, Bioorg. Med. Chem. Lett. 10 (2000) 847.

[4] I. Renard, H. Li, B. Marsan, Electrochim. Acta 48 (2003) 831.

[5] K. Uchida, T. Shike, H. Kakushi, H. Takase, Y. Nomura, T. Harauchi, T. Yoshizaki, Thrombosis Res. 39 (1985) 741.

[6] I.R. Dunkin, C.J. Shields, H. Quast, Tetrahedron 45 (1989) 259.

[7] G. Maier, J. Eckwert, A. Bothur, P. Reisenauer, C. Schmidt, Liebigs Ann. (1996) 1041.

[8] F. Billes, H. Endrédi, G. Keresztury, J. Mol. Struct. (Theochem) 530 (2000) 183.

[9] S. Bugalho, E. Maçôas, L. Cristiano, R. Fausto, Phys. Chem. Chem. Phys. 3 (2001) 3541.

[10] S. Bugalho, A. Serra, L. Lapinski, L. Cristiano, R. Fausto, Phys. Chem. Chem. Phys. 4 (2002) 1725.

[11] S. Bugalho, L. Lapinski, L. Cristiano, L. Frija, R. Fausto, Vibrat. Spectrosc. 30 (2002) 213.

[12] A. Gómez-Zavaglia, I.D. Reva, M.L. Cristiano, L. Frija, R. Fausto, J. Phys. Chem. A 109 (2005) 7967.

[13] E. Shouji, D. Buttry, J. Phys. Chem. B. 102 (1998) 1444.

[14] F. Hipler, R. Fischer, Müller, J. J. Chem. Soc. Perkin Trans. 2 (2002) 1620.

[15] A.R. Katritzky, J. Borowiecka, W.-Q. Fan, L.H. Brannigan, J. Heterocycl. Chem. 28 (1991) 1139.

[16] J.W. Bats, Acta Crystallogr, B 32 (1976) 2866.

[17] J.H. Looker, N.A. Khatri, R.B. Patterson, C.A. Kingsbury, J. Heterocycl. Chem. 15 (1978) 1383.

[18] H. Quast, U. Nahr, Chem. Ber. 118 (1984) 526.

[19] A. Awadallah, K. Kowski, P. Rademacher, J. Heterocycl. Chem. 34 (1997) 113
[20] J.B. Christensen, A. Holm, Acta Chem, Scand. 51 (1997) 527.

[21] R. Flammang, M. Barbieux-Flammang, P. Gerbaux, C.T. Pedersen, J. Chem. Soc. Perkin Trans. 2 (1997) 1261.

[22] I. Alkorta, J. Elguero, Struct. Chem. 14 (2003) 377.

[23] I.D. Reva, S. Stepanian, L. Adamowicz, R. Fausto, J. Phys. Chem. A 105 (2001) 4773.

[24] M. Frisch, G. Trucks, H. Schlegel, G. Scuseria, M. Robb, J. Cheeseman, V. Zakrzewski, J. Montgomery, R. Stratmann, K. Burant, S. Dapprich, J. Millam, A. Daniels, K. Kudin, M. Strain, O. Farkas, J. Tomasi, V. Barone, M. Cossi, R. Cammi, B. Mennucci, C. Pomelli, C. Adamo, S. Clifford, J. Ochterski, G. Petersson, P. Ayala, Q. Cui, K. Morokuma, D. Malick, A. Rabuck, K. Raghavachari, J. Foresman, J. Cioslowski, J. Ortiz, A. Baboul, B. Stefanov, G. Liu, A. Liashenko, P. Piskorz, I. Komaromi, R. Gomperts, R. Martin, D. Fox, T. Keith, M. Al-Laham, C. Peng, A. Nanayakkara, M. Challacombe, P. Gill, B. Johnson, W. Chen, M. Wong, J. Andres, C. Gonzalez, M. Head-Gordon, S. Replogle, J. Pople, (1998) Gaussian 98 , Revision A.9; Gaussian Inc.: Pittsburgh, PA.

[25] A.D. Becke, Phys. Rev. A 38 (1988) 3098.

[26] C.T. Lee, W.T. Yang, R.G. Parr, Phys. Rev. B 37 (1988) 785.

[27] P. Csaszar, P. Pulay, J. Mol. Struct. (Theochem.) 114 (1984) 31.

[28] J.H. Schachtschneider, (1969) Technical Report; Shell Development Co. Emeryville, CA.

[29] R. Fausto, J.J.C. Teixeira-Dias, P.J. Tonge, P.R. Carey, J. Mol. Struct. 324 (1994) 113.

[30] B. Bak, O.J. Nielsen, H. Svanholt, J.J. Christiansen, J. Mol. Spectrosc. 39 (1979) 134.

[31] R. Fausto, L.A.E. Batista de Carvalho, J.J.C. Teixeira-Dias, M.N. Ramos, J. Chem. Soc. Faraday Trans. 2. 85 (1989) 1945.

[32] J. Durig, J. Sullivan, D. Durig, S. Cradock, Can. J. Chem. 63 (1985) 2000.

[33] R.G. Lett, W.H. Flygare, J. Chem. Phys. 47 (1967) 4730.

[34] R.F. Curl Jr., V.M. Rao, K.V.L.N. Sastry, J.A. Hodgeson, J. Chem. Phys. 39 (1963) 3335.

[35] J. Koput, Chem. Phys. Lett. 242 (1995) 514.

[36] R. Fausto, I.D. Reva, L. Lapinski, Abstracts of the XX IUPAC Symposium on Photochemistry, Granada, 2004, pp. 280.

[37] H. Himmel, M. Junker, H. Schnöckel, J. Chem. Phys. 117 (2002) 3321.

[38] G. Pimentel, S. Charles, K. Rosengren, J. Chem. Phys. 44 (1966) 3029.

[39] D. Milligan, M. Jacox, J. Chem. Phys. 41 (1964) 2838.

[40] C. Moore, K. Rosengren, J. Chem. Phys. 44 (1966) 4108.

[41] W. Zhizhong, J. Mol. Struct. (Theochem.). 434 (1998) 1.

[42] J.F. Ogilvie, Can. J. Chem. 46 (1968) 2472.

[43] J. Crovisier, BASEMOL-'Constants for Molecules of Astrophysics Interest in the Gas Phase: Photodissociation, Microwave and Infrared Spectra', Laboratoire d'Études Spatiales et d'Instrumentation en Astrophysique, Observatoire de Paris-Meudon, France, 2002. http:// www.usr.obspm.fr/ crovisie/basemole/

[44] M. Rozenberg, Spectrochim. Acta A 52 (1996) 1559.

[45] M. Rozenberg, G. Shoham, I. Reva, R. Fausto, Spectrochim. Acta A 60 (2004) 463.

[46] M. Rozenberg, G. Shoham, I. Reva, R. Fausto, Phys. Chem. Chem. Phys. 7 (2005) 2376 